\title{
LOS TROVADORES E HISPANIA: ¿UNA TEORÍA DE INFLUENCIA TODAVÍA POSIBLE?
}

\author{
Josef PROKOP \\ Universidad de Bohemia del Sur, České Budějovice
}

\begin{abstract}
En): For several centuries scholars have kept considering various theories about the origin of the Occitan troubadours' songs. Our study attempts to reflect the reasons that stand behind the disdain towards one of them - the theory of the influence coming from the Hispanic al-Andalus. The study tries to find answers to counter the usual arguments of critics of this theory. It points out the difficult position of academic scholars who are obliged to cover extended territory of two literary contexts - the Romanic and the Hispano-Arabic. In conclusion, the study attempts to restate the most obvious arguments supporting the theory that are very often neglected by its critics.
\end{abstract}

Keywords (En): Troubadours; al-Andalus; Hispano-Arabic literature; scholarship

Resumen (Es): Ya desde hace siglos se barajan diversas teorías sobre el origen de las canciones de los trovadores occitanos. Nuestro estudio intenta reflexionar sobre las razones de la desatención actual de una de ellas - de la teoría de influencia del al-Ándalus hispano - por una gran parte de los especialistas. Tratamos de delimitar y luego refutar los argumentos habituales de sus críticos y explicar la difícil posición de los estudiosos que intentan abarcar la temática enorme de los dos contextos literarios en liza, el románico y el hispano-árabe. En conclusión recordamos los argumentos más evidentes que suelen ser descuidados por la crítica.

Palabras claves (Es): trovadores; al-Ándalus; literatura hispano-árabe; investigación científica.

Creemos que no sea demasiado temerario suponer que una gran parte de los romanistas estaría de acuerdo en que el fenómeno de los trovadores, sobre todo la faceta formal de sus canciones y el complejo mundo de conceptos del amor cortés (en occitano fin'amor), era en el momento de su aparición considerablemente nuevo en el contexto de la cultura medieval europea. Tanto por lo repentino de su aparición, como por el perfecto estado de sus formas y lo refinado de sus temas. $\mathrm{Y}$ es lógico que esta inesperada novedad plantee, desde hace ya varios siglos, cuestiones sobre la génesis del fenómeno y sobre sus posibles efectos.

La cuestión de los orígenes del fenómeno ha sido examinada desde el siglo XVI y durante los siglos XIX y XX cristalizaron varias teorías que trataban de explicar el nacimiento súbito e inesperado de la «civilización» trovadoresca (BOASE, 1977 : 5-53). En este breve estudio quisiéramos desempolvar una de estas hipótesis del origen de la lírica trovadoresca - la hispano-árabe. Nuestro objetivo es recordar los argumentos ya conocidos que apoyan esta teoría, sin aspirar a una exhaustividad total, y ofrecer una reflexión sobre las razones y las circunstancias que han llevado en general a los críticos a dejarla de lado a la hora de explicar el origen de la poesía trovadoresca.

En principio tenemos que reconocer la dificultad de establecer una lista de estas teorías que sea definitiva y generalmente aceptable, puesto que, como era de esperar, el valor de muchas de ellas depende de la interpretación de sus apoyadores. Por lo tanto, a efectos de este artículo vamos a presentar sólo un breve resumen de las más frecuentes. Utilizaremos para esto el panorama de Gerald A. BOND (1995), que se apoya a su vez de la muy lograda síntesis de Roger BOASE (1977). Además tomaremos en cuenta un artículo relativo al tema de María Rosa 
Los trovadores y al-Ándalus: ¿una teoría de influencia todavía posible?

MENOCAL (1981) y, naturalmente, el estudio trovadoresco de Martín de RIQUER (1975) que forma el prólogo de su antología monumental.

Para situar al lector en el debate crítico sobre la cuestión, vamos a presentar muy concisamente $-\mathrm{y}$ por lo tanto necesariamente con muchas simplificaciones seis teorías sobre el origen de las canciones trovadorescas más frecuentemente apoyadas por los especialistas. Como la primera podríamos mencionar la teoría del origen vinculado con la tradición literaria latina, tanto antigua como medieval. El más conocido partidario de la primera sería sin duda SCHEDULKO (1940) que en las canciones trovadorescas encuentra una influencia directa de conceptos de amor de las poesías de Ovidio o de los diálogos de Platón. En cuanto a la poesía medieval latina, como el simpatizante principal, es obligatorio mencionar a Peter DRONKE (1965-66). Incluso antes de él autores como BRINKMANN (1926) a su vez conectaron esta teoría con poetas medievales de la llamada escuela de Loire, como son Marbod de Rennes o Hildebert de Lavardin.

Otra plausible teoría pone en el centro de atención la influencia del canto litúrgico. Por ejemplo CHAILley (1955) insiste en la forma específica del así llamado versus aquitano del cual podríamos derivar el concepto formal y musical de las canciones trovadorescas, cuyas primeras manifestaciones conservadas aparecen precisamente en Aquitania.

Relacionar las canciones trovadorescas con las versificaciones de clerici vagi es el argumento de la siguiente teoría (que a veces se inserta, igualmente como la últimamente mencionada, en un gran grupo de teorías latinas). Acuñada entre otros por René NeLLi (1974 : 37-40), la teoría advierte el cambio de la manera de concebir el amor y de describirlo en algunas de las canciones de los vagantes tal como lo sugiere el más famoso ejemplo, la canción anónima «Invitatio amicae».

El núcleo de la teoría de origen cátaro de las canciones trovadorescas estriba según BOASE (1977 : 77-81) en dos argumentos: los principios del movimiento cátaro proporcionan una explicación natural de la peculiaridad de la fin'amor trovadoresca y la desaparición de la civilización cátara por causa de las cruzadas contra los albigenses coincide notablemente con la decadencia y desaparición del mundo trovadoresco.

Mientras que la teoría de la influencia de las canciones populares relacionadas con el ritual de la llegada de la primavera fundada sobre todo por Alfred JEANROY (1889) destaca la importancia de melodías populares y rituales para el nacimiento de las canciones trovadorescas. La argumentación original de Jeanroy según Bond ya ha envejecido un poco, no obstante el descubrimiento de las jarchas a mediados del siglo XX ofreció a esta teoría una nueva vida.

Y como última, mencionemos la teoría que se basa en los pasajes de las canciones trovadorescas en los cuales los conceptos de la relación feudal entre el señor y su vasallo sirven de modelo para el comportamiento y los rituales entre el trovador y su dama. RIQUER (1975 : 80) en este contexto menciona por ejemplo una muy elocuente canción de Guilhem de Berguedá «Lai de hom mellur'e reve».

Al lado de estas teorías suele aparecer también la de la influencia de la tradición poética y cortesana de al-Ándalus. A ella o más bien a los críticos de ella quisiéramos dedicar las líneas siguientes.

No obstante antes de que vayamos más lejos nos gustaría señalar que si bien defendemos la pertinencia de la teoría hispano-árabe eso no quiere decir que la 
consideramos como la única y exclusiva explicación de los orígenes de la civilización de trovadores y de la fin'amor. Es más, los partidarios de las restantes teorías no siempre declaran de una manera explícita y unívoca, y consecuentemente éstas dan la impresión de que son exclusivas y que su aceptación niega la aplicabilidad de otras. Creemos que es bastante obvio que la formación de la civilización trovadoresca es producto de toda una serie de factores resumidos en teorías aquí mencionadas e incluso nuestras. Además el tema de la fin'amor es muy complejo y baste recodar que el corpus de las canciones trovadorescas no es en absoluto uniforme y que muchos de los trovadores entienden a su manera incluso los más básicos conceptos del amor cortés.

El motivo principal de esta reflexión es el hecho de que, aunque la teoría de origen hispano-árabe fue definitivamente formulada ya en el siglo XIX, ésta y algunos de sus argumentos principales que consideramos bastante lógicos y consistentes, siguen siendo tratados con leve indiferencia. Los adversarios de la teoría arabista fundan su crítica principalmente en dos objeciones y nuestra intención es de sopesar sus argumentos y recordar otros que son comúnmente conocidos, pero evadidos por la crítica.

La teoría hispano-árabe se basa en la certeza del estrecho contacto e intercambio intercultural entre la civilización árabe-bereber y la europea. Los opositores pretenden socavar precisamente esta certeza y sostienen por lo general y muy frecuentemente dos argumentos: 1) que los miembros de las dos civilizaciones no pudieron intercambiarse sus culturas ya que hablaban idiomas distintos y 2) aunque se entendieran no intercambiarían su cultura puesto que ambas civilizaciones estuvieron enfrentadas irreconciliablemente. En otras palabras, ¿cómo podríamos imaginarnos un intercambio cultural entre enemigos mortales?

Las objeciones parecen muy lógicas y muy fundamentales. Sin embargo, nos parece que un poco pecan de anacronismo. Si miramos con detenimiento el espacio que podría servir de escenario a dicho intercambio, esto es sobre todo la Península Ibérica de los siglos VIII-XI (por lo tanto dos a tres siglos antes de la aparición de otros espacios de contacto creados por las cruzadas en Medio Oriente; dejando aparte la situación particular en la Sicilia árabe) y si confrontamos las mencionadas objeciones con la imagen de modus vivendi en al-Ándalus en los siglos IX-XI tal y como nos la ofrece la historiografía tenemos que constatar que estas objeciones resultan en gran parte inadecuadas. Adelantemos ya en este lugar que el hecho de que los europeos de hoy en día, en la inmensa mayoría, no entendemos el idioma y no conocemos la cultura árabe no significa automáticamente que pasara lo mismo en los siglos IX-XI en la Península Ibérica. Aquel entonces dominada casi en su totalidad por los árabes y con varias regiones y pueblos cristianos viviendo bajo la administración oriental de un lado y con poblaciones bereberes y árabes bajo el poder de los cristianos de otro.

¿A qué modus vivendi de la Península Ibérica me refiero? A partir del comienzo del siglo VIII, el momento de la penetración del elemento árabe-bereber en la Península Ibérica, los próximos 5 ó 6 siglos son escenario no solamente de continua lucha, sino también de incesable intercambio polifacético entre el cristiano y la población semita y bereber. No es lugar aquí para entrar en la compleja y controvertida discusión sobre la trayectoria histórica de España 
personificada por los dos oponentes más insignes, Américo Castro y Claudio Sánchez-Albornoz. ${ }^{1}$ No obstante se entiende fácilmente por el tema de estas líneas que nuestra visión se inclina hacia el concepto castriano, es decir, que concebimos esta época de al-Ándalus como período de intercambio cristiano-semítico en el campo político, linguiístico y también cultural.

Grandes grupos de poblaciones románicas se vieron forzadas a vivir en contacto permanente con sus vecinos arábigos y al revés. Los ejemplos de los mozárabes (dejamos aparte su eventual evolución en muladíes precisamente por dejar de ser cristianos) y los mudéjares, dos resultados de esta compenetración geográfico-cultural, demuestran claramente que nuestra óptica del siglo XXI que nos hace creer en una rivalidad absoluta y frontal entre las dos civilizaciones es errónea. Los ejemplos mencionados bien ilustran la situación en la Península Ibérica donde hubo comunidades que vivían bajo la autoridad administrativa de otra cultura y otra lengua, y que precisamente por eso tuvieron que comunicarse y entenderse lingüística y culturalmente. Además el caso mozárabe indica claramente cuál de las dos civilizaciones representaba en aquel momento la cultura más desarrollada.

Recordemos que dicha penetración no se limita a la población de labradores o artesanos. Diversos autores acumulan detalles históricos que atestiguan una similar compenetración y contacto incluso en las capas dirigentes de la sociedad. GALMÉS DE FUENTES (1996 : 65) por ejemplo recuerda al historiador ibn Bassam (s. XII) el cual en su recopilación historiográfica Dajira da noticia de la boda del conde don Ramón de Barcelona que se casa con la hija de don Sancho de Castilla y esta boda se celebra en Zaragoza, en el palacio de un rey musulmán Mundir ibn Yahya «en presencia de una gran afluencia de gentes de las dos religiones» (ibid.). Y podríamos seguir. El mismo Alfonso VI de León, el del Cid, sufrió un exilio en su juventud en el Toledo musulmán y luego vivía en concubinato (o matrimonio, inconclusa todavía la discusión de los especialistas) con la famosa mora Zaida. Según GALMÉS DE FUENTES (1996 : 68) es por consiguiente muy lógico suponer que el rey conocía por lo menos algo de la cultura y lengua árabes.

Creemos que incluso por estos incompletos argumentos queda bastante evidente que en la Península Ibérica no existió algo así como una separación absoluta de los dos elementos - románico y semita - y que encontramos datos concretos que nos atestiguan por lo menos una parcial comprensión lingüística entre las dos culturas.

Es cierto que en consecuencia salta inmediatamente a la vista otro de los puntos sensibles de la teoría hispano-árabe. Esto es la conexión de la supuesta cuna del cantar trovadoresco en Peitieu occitánico con al-Ándalus y su mencionado modus vivendi. Pero otra vez es probablemente un anacronismo de nuestros tiempos. Podríamos enlazar el argumento directamente con lo dicho arriba y recordar el primer matrimonio de Alfonso VI de León que se casó en 1069 con Inés (Agnes) de la familia de los duques de Aquitania. Precisamente de esta dinastía más tarde nacerá el primer trovador con obra conocida, Guilhem de Peitieu. Con este ejemplo quisiéramos no más que hacer notar que el mundo aristocrático de entonces - y los aristócratas fueron los mecenas fundamentales de

\footnotetext{
${ }^{1}$ Estamos aludiendo sobre todo a las obras fundamentales del debate de Castro (1954) y de SánchezAlbornoz (1956).
} 
Los trovadores y al-Ándalus: ¿una teoría de influencia todavía posible?

la cultura trovadoresca - no conocía fronteras políticas y lingüísticas que a nosotros nos parecen infranqueables. Y para muchos aristócratas al norte de los Pirineos la reconquista de al-Ándalus fue una buena ocasión para dirigir sus ambiciones militares y políticas.

Un dato incluso mucho más convincente quizás sería la conocidísima anécdota ya directamente relacionada con el primer trovador. Está conectada con la conquista de Barbastro (1064) y con las cautivas moras que se llevaron los vencedores al norte. Según DOZY (1881 : 348 y 341), el geógrafo Yaqut nos informa en su Diccionario geográfico que los conquistadores de Barbastro se llevaron millares de cautivas cantoras de poesía árabe (qaynas) a Francia y otro historiador, ibn Hayyan, completa la información diciendo que al capitán de la caballería del Papa, Guillermo VIII duque de Aquitania (padre del trovador), le correspondieron quinientas de éstas. ${ }^{2}$

Aún si reducimos los números sin duda fantasiosos de los cronistas antiguos, estamos ante una sólida confirmación de la presencia de la lengua árabe en la corte peitavina y de la poesía árabe cantada en el vivero de la futura cultura trovadoresca.

Además - y esto es argumento de otra índole pero fundamental para la cuestión - parece que es innecesario buscar pruebas de un bilingüismo áraberomance en Occitania, ni siquiera un cabal entendimiento de las dos lenguas. Eruditos como María Rosa MENOCAL (1981: 57) o Francisco RICO están convencidos de que una transferencia intercultural de canciones oralmente presentadas no necesita un perfecto conocimiento de la lengua de la canción. ¿Porqué?

Primero, la melodía no necesita traducción. Segundo, la estructura interna de la canción queda aparente por la distribución de rimas u otras repeticiones vocalarmónicas (recordemos que tanto moaxaja como zéjel - los géneros más citados como potenciales predecesores de las canciones trovadorescas - utilizan rimas). Y por último, aun sin un conocimiento sólido y detallado de la lengua de las canciones, cada devoto de esta novedad está informado ya por el eco de la moda, bien o superficialmente, sobre la tonalidad y los conceptos de la misma y sabe balbucear tres o cuatro palabras-emblemas que los representan.

La versión riquiana del argumento que quizás ya anteriormente hubiera formulado también María Rosa MENOCAL (1981 : 57) ofrece una analogía aparentemente anacrónica con la moda de la música rock en la España de los $60^{\mathrm{a}}$ y $70^{\mathrm{a}}$ del siglo XX. Pocos españoles de entonces, decía Francisco RICO, ${ }^{3}$ eran capaces de comprender una frase entera en inglés, pero a pesar de esto la mayoría de los jóvenes estaba entusiasmada por las palabras exóticas procedentes de la cultura rock'n'roll de moda: «love», «sex» etc. y fue capaz de interpretar todo el fenómeno a través de su perspectiva. Creemos que no es temerario imaginarse que la situación de la nueva moda de canciones del siglo X u XI fue muy parecida.

Como hemos visto los argumentos que se oponen a la primera objeción explícita o implícitamente responden también a la segunda que sugiere que dos

\footnotetext{
${ }^{2}$ El dato lo recoge también Menéndez PIDAL (1960 : 331-332) y GALMÉS DE FUENTES (1996 : 67).

3 Observación comunicada durante un curso académico sobre la literatura medieval española en la Universidad Autónoma de Barcelona en otoño de 1999.
} 
Los trovadores y al-Ándalus: ¿una teoría de influencia todavía posible?

civilizaciones irreconciliablemente enfrentadas no intercambian sus fenómenos culturales.

Como una respuesta inmediata podría servir el modus vivendi de la Península Ibérica que hemos esbozado al comienzo de nuestra reflexión. Creemos que el ejemplo de los reinos cristianos españoles en la época de la Reconquista, con los muladíes, la arquitectura mozárabe, los gobernantes cristianos arabizados, la literatura aljamiada, etc., ofrece una clara respuesta a la pregunta de si tal contacto entre dos civilizaciones enfrentadas ideológicamente y políticamente podría tener lugar.

Pero existe otro argumento todavía más persuasivo de María Rosa Menocal al cual ya aludimos arriba.

En este caso usa como término de comparación la influencia y expansión del mismo rock'n'roll en la Rusia comunista. Menocal se basa en estudios monográficos sobre Rusia y señala que en los años 80 del siglo XX la juventud rusa no sólo estuvo dispuesta a pagar en el mercado negro precios exorbitantes por los pantalones vaqueros, pero también con mucho gusto imitaba el rock'n'roll americano, «the lyric poetry of the decadent West», como dice (MENOCAL, 1981 : 57). Y luego propone una comparación. Los futuros historiadores que se ocuparán del siglo XX encontrarán una gran cantidad de documentos en la prensa, la televisión, la radio, los catálogos de las empresas discográficas, los programas de conciertos etc. que traerán datos abundantes sobre un firme rechazo de las tendencias de la música occidental en la Rusia de entonces. Y al mismo tiempo encontrarán en el ámbito no-oficial, «popular» de la cultura rusa una música que tendrá muchos rasgos en común con el rock'n'roll occidental.

Si procedieran de la misma manera como los opositores de la teoría hispanoárabe, tendrían que concluir que el rocanrol ruso tuvo que nacer como resultado de una ingeniosa combinación de las canciones populares rusas y de su gran tradición de música clásica. ¿Por qué? Porque la influencia «occidental» de esta música queda claramente excluida por los documentos mencionados.

Nos parece que estas extrapolaciones ofrecen argumentos que reducen considerablemente el peso de las mencionadas objeciones contra la teoría hispanoárabe. ¿Por qué entonces una gran parte de la comunidad de expertos rechaza en bloc esta hipótesis?

Aquí llegamos al centro de nuestro tema. Creemos que la razón principal para el rechazo implacable de la teoría es la ausencia de expertos preparados adecuadamente para analizar el problema en su totalidad (incluyendo al autor de estas líneas, hay que decirlo). Como es evidente, el terreno en el que se mueve esta teoría se encuentra exactamente a medio camino entre la filología románica y árabe. Los romanistas interesados en la problemática de los orígenes de la primera lírica románica lógicamente no tienen grandes conocimientos en la historia de la literatura y la cultura árabes, por no hablar de la incomprensión del idioma. Por otro lado, los arabistas - aún los de origen europeo o incluso románico - entienden sólo con dificultades la compleja y detallada problemática de las primeras apariciones de la literatura en romance. En primer lugar porque la evolución literaria de su región de interés sigue una cronología totalmente distinta. La literatura árabe remonta sus orígenes a los tiempos pre-coránicos (RUBIERA MATA, 1992 : 49) y durante los siglos X y XI - el período crucial para la literatura 
Los trovadores y al-Ándalus: ¿una teoría de influencia todavía posible?

románica - no acaecen ningunos cambios importantes desde su perspectiva. Con excepción del nacimiento de los géneros particulares de la moaxaja y el zéjel ibéricos, los cuales, sin embargo, desde la óptica de la literatura árabe general resultan en este momento bastante periféricos (RUBIERA MATA, 1992 : 33 y ss). Precisamente por eso los arabistas a menudo no comprenden la obsesión de los romanistas por la literatura árabe del siglo XI.

Sin embargo, no podemos echar la culpa por esta falta de preparación a nadie. Ésta se deriva naturalmente de las tradiciones de formación de mencionados campos científicos en las universidades europeas.

El problema además tiene una dimensión más compleja como pone de relieve Federico CORRIENTE (1998) en su valioso libro. Y esto es que ni siquiera los arabistas formados de manera tradicional no se orientan con habilidad en el contexto literario de al-Ándalus, dado que no les será suficiente el conocimiento de la literatura y lengua árabes clásicas. Puesto que al-Ándalus se convirtió, con mucha probabilidad gracias al diálogo con la cultura románica, en un espacio experimental cuyo desarrollo literario tiene características muy diversas de las de la literatura árabe clásica. Esto lo documentan perfectamente las dos ya mencionadas formas poéticas autóctonas - moaxaja y zéjel - que más tarde se harán famosas por todo el mundo arábigo. Y como estas nuevas formas permiten el uso del árabe regional andalusí, el exclusivo conocimiento del árabe clásico literario tampoco les servirá para estudiar las particularidades de la literatura y cultura en detalle.

De lo dicho resulta que esta problemática queda tratada sobre todo por los arabistas españoles (no olvidando a grandes expertos provenientes de otras naciones como Reinhart Dozy, Henri Pérès o el checo Alois Richard Nykl) que pueden aplicar sus conocimientos de la lengua y literatura árabes en el contexto de su propia cultura. Basta mencionar por ejemplo al ya citado Federico Corriente, a Álvaro Galméz de Fuentes o a sus eminentes predecesores como Julián Ribera o Emilio García Gómez. Son precisamente estos expertos que señalan los paralelismos insoslayables en los conceptos, versificación o terminología que unen la incipiente literatura románica, las canciones de los trovadores en especial, con la poesía y el contexto social hispano-árabe. Y hay que recordar que a menudo se trata de similitudes y paralelismos que - según nuestro parecer - resultan tan obvios y aparentes que es difícil entender cómo pueden ser rechazados de un plumazo en bloc. Veamos a continuación algunos de ellos.

Para empezar es muy curioso observar que casi todos los elementos constitutivos del concepto del amor cortés trovadoresco (fin'amor), tan nuevo y sin precedentes en Europa, los encontramos en estado cristalino en la poesía cortesana andalusí. Nos referimos aquí sobre todo al concepto de la supremacía absoluta de la amada que contradice rotundamente la tradición anterior de la literatura clásica greco-romana, la cual considera el amor apasionado y sumiso como una trágica locura o como motivo de risa (GALMÉS DE FUENTES, 1996 : 156). Pero también al principio de obediencia y servicio amoroso chocante con la costumbre de la antigüedad literaria greco-romana que entendía las relaciones con la amada sobre todo como ars captatoria y al esencial concepto del sufrimiento gozoso por el amor no correspondido que tan difícilmente se explica en el contexto de la tradición de la literatura europea mientras que en el contexto árabe-persa se 
explica bien, puesto que se puede conectar con la actitud mística del sufrimiento sobrellevado, «según el mito del eterno Deseo, o, en la poesía persa, el mito de la búsqueda de la copa de Djem» (GALMÉS DE FUENTES, 1996 : 24).

Así que el núcleo del fenómeno trovadoresco, que en Europa parece ser algo sin precedentes, algo formado como por arte de magia a partir de la nada, encuentra paralelismos innegables en la poesía del no muy lejano al-Ándalus. Ya sólo este hecho debería convencer a todo especialista de la primera lírica en romance a interesarse en la teoría hispano-árabe y en la literatura árabe en la Península Ibérica en general.

Además las similitudes no terminan aquí. Al lado de las mencionadas arriba podemos discernir otras a nivel léxico-conceptual. En el caso de las canciones trovadorescas se trata otra vez de conceptos claves que llevaron a los romanistas a verter litros de tinta para ofrecer una explicación por lo menos decente de un fenómeno tan nuevo en el contexto europeo que, de otro lado, parece muy común para la literatura arábiga. Como ejemplos podríamos aducir los términos «midons», «senhal» y al género literario de «vidas e razós».

El primero de los mencionados, evolucionado en occitano del latino «meus dominus», lo utiliza el trovador para dirigirse a su amada. La llama «mi señor» en el sentido de la obediencia amorosa aludida arriba y por encima en género masculino (y no el femenino «mi señora»). Se trata de un fenómeno sin grandes tradiciones en el contexto de la literatura greco-latina ni tardomedieval europea que parece sin embargo muy similar al uso de los poetas árabes que suelen denominar a su amada como «sayyídí» («mi señor») o «mawláya» («mi dueño») (GALMÉS DE FUENTES, 1996 : 133). Fijémonos bien que el último mencionado es prácticamente un calco semántico del «midons» occitano.

El segundo término «senhal» (compárese la «señal» castellana de pronunciación idéntica) que significa un apodo poéticamente creado por el trovador para ocultar la identidad real de su amada como por ejemplo «Bels Miralhs», es decir «Bello Espejo» o «Mielhs-de-Be», traducible como «Mejor que buena» del trovador Bertran de Born (RIQUER, 1975 : 697-701). El uso del «senhal» podríamos relacionarlo con una muy similar práctica de los nombres inventados de las amadas en la poesía latina, el ejemplo conocidísimo de éstos sería la Lesbia de Catullo. No obstante, la manera de formar estos apodos en el contex to de la poesía latina es considerablemente distinta de la occitana que parece muy cercana al término y concepto conocido en la poesía árabe como «kináya», es decir, un «enigma, símbolo» (GALMÉS DE FUENTES, 1996 : 148-149). Puesto que en el uso trovadoresco la «senhal» también suele de alguna manera caracterizar a la amada, aludir a sus hechos o costumbres típicos, concepto que no encontramos en el caso de los apodos de amadas latinas. En breve el «senhal» ofrece un rompecabezas de ingenio que oculta a la dama de manera bastante parecida a la «kináya» árabe.

Como tercer y último ejemplo quisiéramos mencionar al género de «vidas» (su sentido en castellano es obvio) y «razós» («razones», es decir «explicaciones») tan particular en el contexto de la literatura europea. Prestar en el siglo XI-XII algún interés al autor literario, que es ni más ni menos que el autor de una canción frívola de amor, es un fenómeno bastante novedoso para la Edad Media europea. Y redactar sus breves vidas y explicaciones de sus canciones en los siglos XIII-XIV 
Los trovadores y al-Ándalus: ¿una teoría de influencia todavía posible?

tampoco es demasiado frecuente. Sin embargo, en el contexto de la poesía árabe las «razós» que prologan, por decirlo así, a diversos poemas aparecen muy frecuentemente. Este género queda denominado «jábar» y RUBIERA MATA (1992 : 50) transcribe como ejemplo uno muy hermoso recogido en Al-'Iqd al-Farid (El collar único, antología del siglo IX-X) que narra precisamente la historia y las circunstancias de la composición de una casida del poeta pre-islámico Imru-1Qays. «Jábar» entonces aparenta tener en la literatura árabe un papel paralelo a la «razó» que introduce una canción trovadoresca. Y RUBIERA MATA (1992 : 51) añade que varios «jábares» referentes a un poeta luego iban construyendo una biografía novelesca del autor. Famosos poetas árabes se convirtieron así en figuras arquetípicas y legendarias de modo parecido a algunos de los trovadores como Jaufré Rudel, el cantor del amor lejano, o Guilhem de Cabestanh, el del corazón comido. El nuestro Imru-1-Qays aparecerá así descrito como el príncipe hedonista por antonomasia, otro poeta, 'Antara, como el caballero perfecto etcétera.

Para terminar aludiremos a un documento que podría servir como importante argumento en nuestro debate. Se trata de una iluminación conocida por los especialistas, pero muy raramente citada como un testimonio a favor de la teoría hispano-árabe.

Me refiero a la iluminación del códice escurialense (E) que contiene las Cantigas de Santa María parcialmente atribuidas al famoso rey castellano Alfonso X el Sabio (1221-1284) y a su scriptorium. El códice cuenta con decenas de iluminaciones y la mencionada se encuentra entre la cantiga número 119 «Como somos por conssello do demo perdudos» y la número 120 «Quantos me creveren loarán» y representa a dos juglares que cantan y tocan conjuntamente (reproducida en GALMÉS DE FUENTES, 1996 : 4). Lo curioso de la imagen es que uno de los músicos es evidentemente un oriental, juzgando por la tez más oscura y el hecho de que cubre su cabeza con un tipo de pañuelo enrollado, y el otro un europeo. Ambos tocan un instrumento de cuerda con un mástil (un tipo de instrumentos introducido en Europa precisamente por los árabes) y el europeo con boca abierta parece que acompaña la melodía con su canto.

¿Hace falta buscar otro documento más elocuente para evidenciar la existencia de un repertorio común de los juglares orientales y europeos? ¿Y si hay un repertorio común, no queda así sugerida la posibilidad de una mutua influencia entre las dos culturas aparentemente enemistadas y aparentemente incomprendidas por sus diferencias lingüísticas? ¿Y si hay un repertorio común, no se podrían inspirar las canciones trovadorescas de una manera más o menos intensa en la poesía cortesana de al-Ándalus que estaba de moda? ¿Si fuera así, no sería aprovechable conocer más detalladamente la literatura árabe tanto clásica como la andalusí a la hora de sacar conclusiones sobre la esencia de las canciones trovadorescas?

Como hemos dicho al principio de esta reflexión, el fenómeno trovadoresco no se puede explicar únicamente por una de las teorías mencionadas más arriba. Sin duda confluyeron muchas en formarlo. Abogamos aquí solamente por considerarlas todas con el mismo respeto. 


\section{BIBLIOGRAFÍA}

BOASE Roger (1977), The Origin and Meaning of Courtly Love: A Critical Study of European Scholarship, Manchester, Manchester University Press.

Bond Gerald A. (1995), «Origins», in: AKEHURST F. R. P., DAVIS Judith M. (ed.), A handbook of the Troubadours, Berkeley-Los Angeles, Univ. of California Press, p. 231-249.

BRINKMANN Hennig (1926), Entsthungsgeschichte des Minnesangs, Halle, Niermeyer.

CASTRO Américo (1954), La realidad histórica de España, México, Porrúa.

Chailley J. (1955), «Les premiers troubadours et le Versus de l'école d'Aquitaine», Romania LXXVI, p. 212-339.

CORRIENTE Federico (1998), Poesía dialectal árabe y romance en Alandalús (cejeles y «xarajat» de «muwassahat»), Madrid, Gredos.

DoZY Reinhart P. A. (1881), Recherches sur l'histoire et la littérature de l'Espagne pendant le moyen âge, 3 a ed., Leyde.

DRONKE Peter (1965-1966), Medieval latin and the rise of european love-lyric, 2 vols., Oxford, Clarendon Press.

GALMÉS DE FUENTES Álvaro (1996), El Amor cortés en la lírica árabe y en la lírica provenzal, Madrid, Cátedra.

JEANROY Alfred (1889), Les origines de la poésie lyrique en France au Moyen Âge, Paris, Hachette.

MENÉNDEZ PIDAL Ramón (1960), «La primitiva lírica europea», Revista de filología española XLIII, p. 331-332.

MenOCAL María Rosa (1981), «Close encounters in Medieval Provence: Spain's role in the birth of troubadour poetry», Hispanic Review 49, n 1, p. 43-64.

Nelli René (1974), L'érotique des troubadours, 2 vols., Union Générale d'Éditions, Bibliothèque 10/18.

RIQUER Martín de (1975), Los trovadores, 3 vols., Barcelona, Planeta.

RUBIERA MATA María Jesús (1992), Literatura hispanoárabe, Madrid, MAPFRE.

SÁNCHEZ-AlBORNOZ Claudio (1956), España, un enigma histórico, Buenos Aires, Editorial Sudamericana.

SCHEDULKO Dimitri (1940), «Ovid und die Troubadours», Zeitschrift für romanische Philologie 60, p. 191-234.

Venantius Fortunatus (1998), Poèmes, trad. Marc Reydellet, Paris, Les Belles Lettres. 